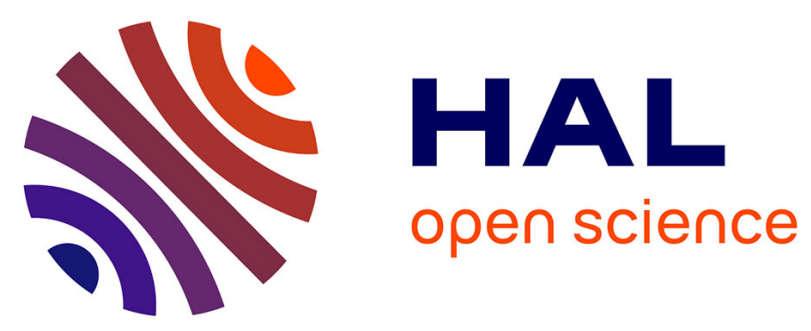

\title{
Morphology of the Iceland Basin Excursion from a spherical harmonics analysis and an iterative Bayesian inversion procedure of sedimentary records
} Luca Lanci, Catherine Kissel, Roman Leonhardt, Carlo Laj

\section{- To cite this version:}

Luca Lanci, Catherine Kissel, Roman Leonhardt, Carlo Laj. Morphology of the Iceland Basin Excursion from a spherical harmonics analysis and an iterative Bayesian inversion procedure of sedimentary records. Physics of the Earth and Planetary Interiors, 2008, 169 (1-4), pp.131. 10.1016/j.pepi.2008.06.004 . hal-00532153

\section{HAL Id: hal-00532153 \\ https://hal.science/hal-00532153}

Submitted on 4 Nov 2010

HAL is a multi-disciplinary open access archive for the deposit and dissemination of scientific research documents, whether they are published or not. The documents may come from teaching and research institutions in France or abroad, or from public or private research centers.
L'archive ouverte pluridisciplinaire HAL, est destinée au dépôt et à la diffusion de documents scientifiques de niveau recherche, publiés ou non, émanant des établissements d'enseignement et de recherche français ou étrangers, des laboratoires publics ou privés. 


\section{Accepted Manuscript}

Title: Morphology of the Iceland Basin Excursion from a spherical harmonics analysis and an iterative Bayesian inversion procedure of sedimentary records

Authors: Luca Lanci, Catherine Kissel, Roman Leonhardt, Carlo Laj

PII: S0031-9201(08)00113-1

DOI:

Reference: doi:10.1016/j.pepi.2008.06.004

To appear in: PEPI 4956

Received date:

Revised date: Physics of the Earth and Planetary Interiors

Accepted date:

$$
\begin{aligned}
& 31-1-2008 \\
& 15-5-2008
\end{aligned}
$$

2-6-2008

Please cite this article as: Lanci, L., Kissel, C., Leonhardt, R., Laj, C., Morphology of the Iceland Basin Excursion from a spherical harmonics analysis and an iterative Bayesian inversion procedure of sedimentary records, Physics of the Earth and Planetary Interiors (2007), doi:10.1016/j.pepi.2008.06.004

This is a PDF file of an unedited manuscript that has been accepted for publication. As a service to our customers we are providing this early version of the manuscript. The manuscript will undergo copyediting, typesetting, and review of the resulting proof before it is published in its final form. Please note that during the production process errors may be discovered which could affect the content, and all legal disclaimers that apply to the journal pertain. 


\section{Morphology of the Iceland Basin Excursion from a spherical harmonics analysis and an iterative Bayesian inversion procedure of sedimentary records.}

Luca Lanci $^{(1)}$, Catherine Kissel $^{(2)^{*}}$, Roman Leonhardt ${ }^{(3)}$, Carlo Laj $^{(2)}$

(1) Istituto di Scienze della Terra, University of Urbino, Campus scientifico SOGESTA, I-61100, Urbino (PU), Italy

(2) Laboratoire des Sciences du Climat et de l'Environnement/IPSL (CEA-CNRS-UVSQ), Avenue de la Terrasse, 91198 Gif-sur-Yvette cedex, France

(3) Department of Applied Earth Sciences and Geophysics, Montanuniversität, Peter-Tunner-Strasse 2527, 8700 Leoben, Austria

* corresponding author (fax: 33-1-69823568; e-mail: kissel@lsce.ipsl.fr)

\section{$\underline{\text { Abstract }}$}

Based on 5 published marine high resolution sedimentary records of the Iceland Basin Excursion (IBE; Channell et al., 1997; Laj et al., 2006) dated around 186-190 kyr, we present models of the excursional geomagnetic field at the Earth's surface using two different approaches. First a spherical harmonics analysis is performed after synchronization of the records using their paleointensity profiles. Second, we have used an iterative Bayesian inversion procedure, calibrated using the single volcanic data available so far. Both modeling approaches suffer from imperfections of the paleomagnetic signals and mostly from the still poor geographical distribution of detailed records, presently available only from the North Atlantic and the West Pacific. For these reasons, our modeling results should only be regarded as preliminary models of the geomagnetic field during the IBE, susceptible to improvements when including results from future paleomagnetic studies. Nevertheless, both approaches show distinct similarities and are stable against moderate variations of modeling parameters. The general picture is that of a dipole field undergoing a strong reduction, but remaining higher than the non-dipole field all through the excursional process, except for a very short interval of time corresponding to the dipole minimum at the center of the excursion. On the other hand, some differences exist between the results of the two models with each other and with the real data when the virtual geomagnetic pole (VGP) paths are considered. The non-dipole field does not appear to undergo very significant changes during the excursion except for a slight increase just at the dipole minimum. The width of mid- 
height of the dipole minimum, which can be considered as an approximate measure of the duration of the IBE is of the order of 3kyr according to the SPECMAP age model, consistent with a suggestion by Gubbins (1999). These results are compared to those obtained for the MatuyamaBrunhes geomagnetic reversal (Leonhardt and Fabian, 2007).

Keywords: geomagnetic excursion, transitional field, Iceland Basin excursion, Spherical Harmonics, Bayesian inversion models

\section{Introduction}

Geomagnetic excursions were generally treated with skepticism as recently as 15 years ago, for several reasons. It was difficult to locate and detect such relatively short geomagnetic events in volcanic sequences, due to the sporadic nature of volcanic eruptions, and also in sedimentary sequences, because short lived events can easily be smoothed out in relatively slowly deposited sediments (Roberts and Winklhofer, 2004). There were also difficulties in precisely correlating excursions at distant sites, making it problematical or impossible to assess whether two excursion records were coeval.

The change in attitude towards excursions began about 15 years ago, when development of new coring techniques, such as the hydraulic piston corer of the Ocean Drilling Program (ODP), or enhanced penetration by other more conventional coring devices, such as the CALYPSO corer on board the R.V. Marion Dufresne operated by the French Polar Institute (IPEV), made possible the recovery of long sequences of high accumulation rate sediments from the deep oceans, thereby enhancing the chances of recording brief polarity excursions. At the same time, improved age control of both young volcanic rocks and sediments allowed to ascertain unequivocally whether excursion records were coeval or not. 
Although obtaining detailed records of excursions is still difficult, today we can be confident of the existence of at least 7 polarity excursions in the Brunhes Chron and perhaps as many as 11 in the Matuyama Chron (Laj and Channell, 2007) and other excursions have been documented prior to the Matuyama Chron. Geomagnetic excursions are therefore intrinsic features of the geodynamo behavior, in addition to being extremely useful as precise stratigraphic markers.

Initially, it was not realized that excursions might have a different nature than reversals, so the VGP paths obtained for the most detailed ones have been considered together with reversal paths, when statistically testing the hypothesis of preferential bands for transitional VGP paths (Laj et al., 1991; Clement et al., 1991; McFadden et al., 1993). More recently, however, processes related to the Earth's inner core were suggested which distinguish between reversals and excursions. Firstly, the "magnetic hypothesis" states that excursions might occur when the field reverses only in the Earth's liquid core, which has timescales of 500 years or so, whereas full geomagnetic reversals occur when the field reverses in both the liquid and solid inner core, this last having time constants of the order of $3 \mathrm{kyr}$ for flux diffusion (Gubbins, 1999). Some numerical geodynamo modeling results disagree with this hypothesis and suggest that the inner core conductivity does not influence the field character (Wicht, 2002). The second "dynamic hypothesis" is related to the different dynamic regimes in the outer core within and outside the tangent cylinder (Hollerbach and Jones, 1993). Fluid motion is assumed to be relatively quiescent within the tangent cylinder, but changes more rapidly outside this region. Excursions might be found when the field reverses only outside of the tangent cylinder. The duration and frequency of excursions relative to reversals, therefore, have the potential for exploring the complex mechanisms associated with the geomagnetic dynamo, in particular for providing information about the time constants of flux diffusion and the coupling between inner and outer cores. 
Moreover, the morphology of the field during the excursions may provide information about the relative amplitude of dipolar versus non-dipolar components dominating the excursional field.

New studies of the two best examined excursions of the Brunhes Chron, the Laschamp and the Iceland Basin Excursions, have been recently reported (Channell, 2006; Laj et al., 2006; Laj and Channell, 2007). Contrary to generally held idea that the low intensity of the excursional field reflects the emergence of non-dipole components, these studies concluded that a relatively simple geometry dominated the transitional field for both excursions, because strikingly similar VGP paths were observed at several geographical distributed sampling locations.

In this article, we examine the Iceland Basin Excursion, by performing a spherical harmonics analysis (SHA) of the excursional field, after synchronization of the directional records using relative paleointensity records. We also apply the iterative Bayesian inversion procedure according to Leonhardt and Fabian (2007), which is hampered by the absence of a detailed volcanic record needed for calibration of the relative paleointensity data. We finally compare the results of the two excursions to those previously obtained for the MatuyamaBrunhes reversal through the use of the Bayesian inversion method.

\section{Selection of the records}

The name of the Iceland Basin excursion originates from the basin where two cores in which this excursion has been recorded were retrieved during ODP Leg 162 (Channell et al., 1997; Channell, 1999). In a recent article, Laj et al. (2006) have considered these two records together with five other records from different sites (Fig. 1 and Table 1). Two of these new IBE records were found in cores collected in North Atlantic during the GINNA IMAGES cruise of the R. V. Marion Dufresne, in the Eirik Drift, south of Greenland, and on the western flank of the Reykjanes Ridge. Two other records obtained from ODP sites 1145 and 1146 (South China Sea) 
were cored during ODP Leg184. Although much less detailed, the record from Lake Baikal (Oda et al., 2002) was also included in the analysis of Laj et al. (2006).

In Laj et al. (2006) only the positions of the transitional VGP paths were considered and, for this purpose the age models available from these records was sufficiently accurate for their comparison. Here, on the other hand, our objective is to obtain a reconstruction of the different dipole and non-dipole terms of the field reigning during the excursion. Under these circumstances it is essential to have a precise synchronization of the records, thus a common as-precise-aspossible age model. Because the IBE has been precisely associated with the transition between marine isotope stages 7 and 6, we have, therefore, chosen to consider among the records used in Laj et al. (2006) only those where both a high-resolution oxygen isotope stratigraphy, based either on planktonic or benthic foraminifera, and a detailed transitional record were available (Fig. 2). These selection criteria, unfortunately, led us to reject the Lake Baikal record (Oda et al., 2002), despite its unique location. Indeed, in this case, the age model, which was derived by the correlation of density as a proxy for biogenic silica content with interglacial periods, was not as accurate as those derived from oxygen isotope stratigraphy. ODP site 984 was rejected for this study because the paleointensity record is very noisy, although the directional changes are well defined. The selected records are all characterized by relatively high sediment accumulation rates, varying from 7 to $15 \mathrm{~cm} / \mathrm{kyr}$, which are well within the range required for adequate recording of excursions in sedimentary environments with shallow lock-in depth (Roberts and Winklhofer, 2004).

\section{Spherical Harmonics Analysis}

As mentioned above, we have selected records for which an oxygen isotope study is available (Fig. 2). Depending on which reference curve these initial records have been reported, 
some age discrepancies exist in the exact age assigned to the IBE. However, our primary purpose here is not to assign a precise absolute age to the IBE but to describe its morphology and duration. So, to achieve the synchronization at very short timescales, one can use oxygen isotope stratigraphy in a first step, then some of the characteristics of the geomagnetic records themselves, namely the directional changes or the relative paleointensity records. We have chosen to do this synchronization using the paleointensity signal rather than directions. This is certainly a subjective choice, however justified by the fact that the (dipole) intensity low is the main characteristic of a geomagnetic excursion, when other phenomena, such as the production of cosmogenic isotopes, are considered. Moreover, directions exhibit more high-frequency features than paleointensity, therefore possible lock-in processes can alter the direction records more than the paleointensity records.

In every record of IBE the excursional paleointensity profile shows a peculiar structure (Fig. 2), with two lows separated by a slight but significant increase of the intensity between them (this structure is a little less marked in core MD99-2242 compared to the others). This double structure is not present in the directional part (inclination) with the exception of ODP site 1145. In the other records the main shift in inclination coincides either with the slight increase in paleointensity (ODP site 983 and MD99-2247) or with the youngest of these lows (ODP site 1146, MD99-2242). We have no ready explanation for this effect that would lead to slightly different results if synchronization is obtained using the directional rather than the intensity records. However, we find hard to believe that it is of geomagnetic origin, because in this case one would expect a similar behaviour at sites MD99-2247 and MD99-2242 which are geographically close, whilst they differ in this respect. Sedimentological factors, such as subtle changes in sedimentation rate or a very small magnetization lock-in depth in some of the records seems more realistic to us. 
As a common time scale for the five available records we have chosen the age model derived from a benthic isotope curve (Clemens and Prell, 2003) from ODP site 1146, and correlated the other four records to this one, using the Analyserie software developed by Paillard et al. (1996). ODP Site 1146 was chosen as master record not only because the precise oxygen isotope record is based on benthic foraminifera but also because this site is the closest to the only available volcanic record of the IBE (see the Bayesian approach below). However, the absolute values of this age model are not more preferable than those (slightly different) of other sites. In fact IBE is dated with respect to marine isotopic stage 7/6 boundary, which is bracketed between $182 \mathrm{kyr}$ and $196 \mathrm{kyr}$ in the SPECMAP reference curve (Imbrie et al., 1984; Martinson et al., 1987) and it is dated between $185 \mathrm{kyr}$ and $192 \mathrm{kyr}$ in the benthic isotope stack published more recently by Lisiecki and Raymo (2005). The age model we used is compatible with these datings.

The five paleointensity records, synchronized in the 178-202 kyr interval on the time scale of site 1146, and scaled to the same average value, are shown in Fig. 3a. A remarkable agreement between the paleointensity records can be visually observed while the directional changes in the inclination records appear not perfectly coeval at all sites (Fig. 3b). As reported in Fig. 3c, the maximum time adjustment involved in this paleointensity-based synchronization among records is always smaller than $2 \mathrm{kyr}$ (attained for ODP site 1145). These differences probably reflect the discrepancies in the initial correlation of each isotope records with the reference SPECMAP curve and in any case they are within the uncertainties of the SPECMAP stratigraphy that can be estimated in a few thousand years.

A further necessary step when using relative paleointensity data is to properly adjust the paleointensity to a common scale independent from sediment magnetic properties. Attempts to obtain an absolute calibration of relative paleointensity data have already been made by several authors (i.e. Constable and Tauxe, 1996; Guyodo and Valet, 1996; Laj et al., 2000; 2004). For the 
present purpose, however, an absolute calibration is not necessary. A common relative scale for the selected five sites is sufficient. For a dipolar field such a scale can be simply deduced from the (magnetic) latitude dependence of the field intensity. Therefore, in agreement with the GAD hypothesis, we assumed that the paleomagnetic field before the excursion, averaged over about 10,000 years, was a dipolar field, thus the averaged, pre-excursional, field intensity should depend only on site latitude. Based on this assumption, we averaged the vector field of relative paleointensity in the same period from about 191 to $197 \mathrm{kyr}$ at each site, and fitted the average field to a dipole at each site to compute the relative $\mathrm{B}_{0} *=\sqrt{ }\left(\left(\mathrm{g}^{0}\right)^{2}+\left(\mathrm{g}_{1}{ }_{1}\right)^{2}+\mathrm{h}\left({ }_{1}\right)^{2}\right)$. Since a dipole was fitted independently at each site the calculation of $\mathrm{B}_{0} *$ does not strictly require an axial dipole, although all computed average dipole axes are found to be very close to the geographical axis. At each site the value of $\mathrm{B}_{0} *$ was then used to rescale the whole record in a way that the average field intensity from $191 \mathrm{kyr}$ to $197 \mathrm{kyr}$ has the (arbitrary) value $\mathrm{B}_{0}=1$. Of course the $\mathrm{B}_{0}$ value during the excursion is expected to vary, according to the field intensity records.

After intensity adjustment and synchronization, the records were linearly interpolated to the time scale of site 1146 and SHA was applied to the full vector paleomagnetic data using standard methods (Backus et al., 1996) in order to find the best-fit dipole coefficient $\left(\mathrm{g}^{0}{ }_{1}, \mathrm{~g}^{1}{ }_{1}, \mathrm{~h}^{1}{ }_{1}\right)$ by mean of the least-square method. Although the number of geographical sites was sufficient to carry a SHA up to order 2 (quadrupole) we have limited the SHA decomposition to the $1^{\text {st }}$ order (dipole) since the clustered geographical distribution of the sites would have led to biased results for higher order harmonics. Therefore the non-dipolar part of the field had to be estimated from the residuals of the dipole best fit, possibly including a relatively large contribution of random errors due to the noise on the paleomagnetic signals. 
We attempted to estimate the confidence level of SHA results by using jackknife statistics (e.g., Shao and $\mathrm{Tu}, 1995)$. This technique consists of removing a given number of sites taken at random from the original data set, in order to obtain subsets of available data. SHA analysis is then applied to all subsets at each time node, obtaining a distribution of parameter from which a confidence interval could be drawn. Because of the small number of available sites (5) we have explored all possible 16 combinations obtained by leaving at least 3 sites for data fitting, then the confidence level that include $95 \%$ of cases from non-parametric distribution of model coefficient was computed at each time node. Although we do not have extensively tested the sensitivity of SHA to synchronization errors we have tried a few slightly different synchronization scenarii and obtained practically the same results, which gives us confidence on the robustness of the SHA model to moderate variations in records interlock. Moreover, jackknife statistics are also sensitive to errors in the synchronization of records and the resulting confidence bands also provide an indirect measure of the accuracy of the synchronization among records and robustness of the method to such errors.

\section{Iterative Bayesian inversion}

In parallel, we have also applied an iterative Bayesian inversion procedure (Leonhardt and Fabian, 2007) in order to obtain a global geomagnetic field model. This inversion scheme requires no a priori assumptions about synchronous features of the two records. Again, the ODP site 1146 record is used as primary record and all further age estimates are based on its time scale and related uncertainty. The application of the inversion procedure requires the relative intensity signals to be calibrated against at least one record of absolute intensity. To our knowledge, the only existing lava record with full vector determinations on a single flow was obtained at Unzen volcano, Japan (Shibuya et al., 2007, Yamamoto et al., 2006). This volcanic record is 
characterized by a transitional direction (Dec: -72.6, Inc: -21.0), referred to as the Senbongi excursion, with a K/Ar age of $197 \pm 17 \mathrm{ka}$ and an absolute intensity value F: $7.6 \pm 1.6 \mu \mathrm{T}$ determined on three samples by Thellier (IZZI) and Microwave techniques. For further analysis, we assume that this field vector provides a volcanic record of the IBE. Thus, it is possible to follow the procedure outlined by Leonhardt and Fabian (2007) for an iterative Bayesian inversion of several IBE records (Fig. 4). Each iteration step of this technique comprises following points: (1) Invert the first paleomagnetic record, (2) calculate a predicted record at the second location from the resulting model and (3) correlate the second record to this prediction.

For application to the IBE, the ODP site 1146 record is firstly inverted. Its inversion solution, which provides a spherical harmonic model, is evaluated for the site location of the Unzen volcano. Based on its direction, the single full vector record can then be matched to the ODP site 1146 record at age $188.26 \mathrm{kyr}$. In a next step, the relative intensities are calibrated by the absolute value, leading to a calibration factor $\alpha_{\mathrm{ODP} 1146}$ of $222 \mu \mathrm{T}$ for the originally (ARM normalized) relative paleointensities computed at the core/mantle boundary. Admittedly, using only a single spot reading of the field this matching leave a rather large uncertainty in the calibration procedure. Nevertheless, the directional correlation is unambiguous within the ODP1146 record and the assigned age is consistent with the uncertainty range of the radiometric age. Additionally, the calibrated intensities appear to be reasonable for the Brunhes period. Inversion of the ODP site 1146 plus the Unzen record leads to a first Inverse Model of the Iceland Basin Excursion IMIBEa (Fig. 4).

In the next step record ODP site 1145 is synchronized to the model prediction of IMIBEa for its location (Fig. 4). Its intensity calibration coefficient is optimized by the inversion routine and corresponds to $\alpha_{\mathrm{ODP} 1145}=262 \mu \mathrm{T}$. Because of the very limited distance between ODP sites 1145 
and 1146, the synchronization by the model prediction does not differ from direct synchronization of the paleomagnetic data, because the model prediction is nearly identical to the initially inverted data set. In order to further test the validity of the intensity calibration and synchronization we changed the order of the incorporated sites within the iterative procedure. When starting the iterative procedure with the ODP site 1145 record, pre-calibration of its relative paleointensity with the absolute value of Unzen leads to an almost identical calibration coefficient $\left(\alpha_{\mathrm{ODP} 1145}=266 \mu \mathrm{T}\right)$ in comparison to its inclusion in the third step. Assuming that the absolute intensity record is indeed from the IBE, this agreement supports the validity of absolute intensity calibration for ODP sites 1145 and 1146.

Therefore, we continue the iterative inversion procedure by matching the three other records from the North Atlantic, MD99-2242, ODP site 983, and MD99-2247 (IMIBEe in Fig. 4). For each additional record, the calibration coefficients are synchronously optimized by the inversion routine. Similar as for the SHA paleointensity synchronization, the maximum time shift needed for adjusting all individual records does not exceed 2 kyrs (Fig. 5). In the whole inversion procedure, which results in the final model IMIBEe based on six independent data sets, each paleomagnetic measurement in a given record is treated as an independent and equally weighted time step. Initial and final boundary conditions $\mathrm{G}_{0}$ and $\mathrm{G}_{1}$ are purely axial dipole fields with field strength of $30 \mu \mathrm{T}$ at the equator. The maximum multipole degree of the spherical harmonic expansion is $\mathrm{L}=5$, leading to 35 variables at each of the $\mathrm{N}=150$ time nodes. The regularization parameter $\Delta \mathrm{E}_{0}=10000$ provides the best trade-off between energy fluctuation minimization and data fit.

\section{Dipolar and non-dipolar components during the excursion}


The energy of dipolar and non-dipolar field components at the Earth's surface is plotted in Fig. 6a and Fig. $6 \mathrm{~b}$ as result from SHA and IMIBEe approaches respectively. As explained above, in this plot and subsequent discussion all ages are related to the time scale of the ODP site 1146 record. The main characteristics of the dipolar components are very similar. In both models before $195 \mathrm{kyr}$ a decrease of the dipole energy is observed, followed by rather constant dipole energies for the next $5 \mathrm{kyr}$. Dipolar terms outweigh the non-dipolar terms significantly until $188.5 \mathrm{kyr}$ as expected for pre-excursional field. The minimum dipolar energy calculated using the SHA approach is quite large, between 189.6 and $187.2 \mathrm{kyr}$, while during the same period, the dipole energy retrieved from the Bayesian approach follows a slightly decreasing plateau reaching the minimum at about $187.2 \mathrm{kyr}$. This minimum is similarly followed in both models by a gradual recover of the original dipole energy, which takes about $3 \mathrm{kyr}$ to reach pre-excursional values. The main view outlined by the two models highlights a dipolar field undergoing a strong reduction but remaining higher than the non-dipole field through the excursional process, except for a short interval of time corresponding to the dipole minimum at about $187.5 \mathrm{ka}$. The other small-scale features of the field energy curves, as well as the minor differences between the two models, are difficult to interpret and likely fall within the uncertainty of the calculations.

Important characteristics of transitional field are shown by plot of the first order (i.e., dipolar) Gauss coefficients (Fig. 6c, d) that display the dipole field evolution during the IBE and point out a significant difference between these two models. According to SHA model the main feature of IBE consists in a decrease of the axial dipole $\left(\mathrm{g}^{0}{ }_{1}\right)$ that reverses its direction between 187.5 and $188.5 \mathrm{kyr}$, and then gradually regains its original energy. During this process the equatorial coefficients $\mathrm{g}_{1}^{1}$ and $\mathrm{h}_{1}^{1}$ fluctuate within the pre-excursional magnitude without significant variations, however combined with low axial dipole $\left(\mathrm{g}^{0}\right)$ during IBE, they result in large directional changes of dipole axis. 
Conversely, the IMIBEe model shows a smaller decrease of the axial dipole component $\left(\mathrm{g}^{0}\right)$, which never reaches positive (i.e., reverse field) values. Similar to the present day field, $g_{1}{ }_{1}$ is mostly negative and $\mathrm{h}_{1}^{1}$ mostly positive and slightly larger than $\mathrm{g}_{1}^{1}$ throughout the modeled time interval. Before the dipole minimum equatorial Gauss coefficients $\mathrm{g}_{1}^{1}$ and $\mathrm{h}^{1}{ }_{1}$ decrease causing the dipole axis to move significantly from the geographical pole during the IBE and the preceding few thousand years, but without crossing the equator.

The different behaviour of the equatorial dipole field in the two models makes an univocal interpretation difficult. However, despite these differences the general picture suggested by the results of both models is that the decrease of field intensity observed during the IBE is a consequence of a reduced dipole field energy that is gradually recovered in the following few thousand years. The period of slow recovery is compatible with suggested inner core diffusion times (Gubbins, 1999) as well as time ranges of delayed field recovery within different dynamic regimes of the outer core as found in numerical simulations (Glatzmaier et al., 1999).

\section{Discussion and conclusions}

Both modeling approaches, the SHA and the iterative Bayesian inversion, suffer from imperfections of paleomagnetic signals in sedimentary records, linked to subtle changes in sedimentation rate or in lock-in depth problems mentioned above and which are difficult to estimate. But the main restriction is likely linked to the still poor geographical distribution of the detailed sites. Paleomagnetic records are available only from the North Atlantic and the West Pacific. For these reasons, our modeling results should only be regarded as preliminary models of the geomagnetic field during the IBE, susceptible to improvements when including future results from further paleomagnetic studies. Nevertheless, our results allow to compare different synchronization approaches. Furthermore, a preliminary analysis of major field components is 
certainly justified because, despite their very different synchronization and modeling techniques, both approaches show distinct similarities and are stable against moderate variations of modeling parameters.

One first difference between the two models is how they deal with the relative values of paleointensity available from sedimentary records. The IMIBEe model needs one absolute paleointensity record to calibrate the first record, which is the ODP site 1146 site from the West Pacific, and then proceed on calibrating all subsequent records to the first. The model turned out to be very stable with respect to changes in the order in which the West Pacific sites were incorporated, as well as slight variations within their synchronization. Therefore, these three records were chosen as the optimal choice for starting the inversion. Even so, one should never forget that intensity calibration is based only on a single volcanic spot reading, which is not unambiguously related to the IBE. The SHA does not need absolute paleointensity values but still needs to recalibrate the records at different sites to a (relative) common value, which is computed according to the rather reasonable assumption of a geocentric dipole average field.

A precise time calibration (interlock) between records is an essential prerequisite of the SHA, which was obtained, prior to the analysis, by correlating relative paleointensity. In the IMIBEe model the site correlation is based on Cartesian component $\mathrm{X}, \mathrm{Y}$, and $\mathrm{Z}$ of vector field. Correlation is done iteratively by mapping each newly included paleomagnetic record onto the field prediction from the inversion results of earlier records. Both interlock methods are, to a certain extent, subjective and turned out to produce different results. In particular during the IBE, when paleointensity variations are small compared to directional changes, the IMIBEe iterative synchronization mainly founds on these directional changes. Conversely the SHA interlock, which is based solely on paleointensity values, disregards directional changes, whose result are then not always synchronous (Fig. 3a, b). 
The different interlock is the most likely reason for the most prominent differences arising from the two models although both of them are compatible with constraints from oxygen isotopes dating.

Compared to results from the last reversal (Leonhardt and Fabian, 2007) distinctive differences are observed for the transitional energy evolution of the field. Prior to the Matuyama/Brunhes reversal a significant increase of non-dipole energy towards the same level as the dipolar field is observed. Such increase is neither observed for the results obtained by the Bayesian modeling approach for the Laschamp excursion (Leonhardt et al., 2007) nor for the here investigated IBE excursion suggesting that this feature could be indicative for reversals. Furthermore, the dipole energy is reduced well below the non-dipolar value during the Matuyama/Brunhes reversal compared to Laschamp and IBE excursions. Nevertheless, the reduced dipole intensity (compared to non-excursional field) during the IBE implies that the field looses some of its dipolar feature that is a characteristic of the stable geomagnetic field. The comparison of VGP paths computed from single sites assuming a fully dipolar field (Laj et al. 2006) with the dipole path predicted by SHA and IMIBEe models (Fig. 7) give dissimilar results. There is a similitude between the dipole path calculated from the SHA and those reported in Laj et al. (2006) with a short diversion corresponding to the peak of non-dipole energy at $188.6 \mathrm{kyr}$ (Fig. 5a). This could suggest that the dipole field has a strong influence on paleomagnetic directions during the excursion despite its low intensity. However such an interpretation is not supported by the IMIBEe results and thus must be treated with great care. Given the above mentioned restrictions and uncertainties in the models we conclude that it is not yet possible to provide reasonable global field predictions and detailed structural analyses or the transitional field. Therefore, it cannot yet be answered whether or not the dipole field remaining during the excursion is able to register transitional VGP paths similar to those found by Laj et al. (2006) for 
other sampling locations on Earth. New records of IBE from different geographic locations and recording media are urgently needed to confirm our hypotheses and to improve the models reliability and robustness.

Acknowledgments. This work was supported by the French Atomic Energy Commission and the Centre National de la Recherche Scientifique and the German science foundation (DFG grant Le1905/1-1). We are grateful to J. Channell, H. Oda, E. Cortijo, S. Clemens, K. McIntyre, D. Oppo and C. Hillaire-Marcel for providing numerical data. We are also grateful to two anonymous referees and to Prof. Yongxin Pan for helping in improving the manuscript. The two MD99- cores were retrieved by the R. V. Marion Dufresne operated by the French Polar Institute (IPEV) within the framework of the IMAGES program (Ginna cruise), the two ODP sites from the North Atlantic during the Leg 162 and the two ODP sites from the South China Sea during the Leg 184. 


\section{References}

Backus, G., Parker, R., and Constable, C., 1996. Foundations of Geomagnetism. Cambridge University Press, Cambridge, 370 pp.

Channell, J. E. T., Hodell, D. A., and Lehman, B., 1997. Relative geomagnetic paleointensity and $\partial^{18} \mathrm{O}$ at ODP Site 983/ Gardar Drift, North Atlantic since 350 ka. Earth Planet. Sci. Lett., 153: $103-118$.

Channell, J. E. T., Hodell, D. A., McManus, J., Lehman, B., 1998. Orbital modulation of the Earth's magnetic field intensity. Nature, 394(6692): 464-468.

Channell, J. E. T., 1999. Geomagnetic paleointensity and directional secular variation at Ocean Drilling Program (ODP) Site 984 (Bjorn Drift) since 500 ka: Comparisons with ODP Site 983 (Gardar Drift). J. Geophys. Res., 104: 22937-22951.

Channell, J. E. T., 2006. Late Brunhes polarity excursions (Mono Lake, Laschamp, Iceland Basin and Pringle Falls) recorded at ODP Site 919 (Irminger Basin). Earth Planet. Sci. Lett., 244: 378-393.

Clemens, S.C., and Prell, W.L., 2003. Data report: Oxygen and carbon isotopes from Site 1146, northern South China Sea. In Prell, W.L., Wang, P., Blum, P., Rea, D.K., and Clemens, S.C. (Eds.), Proc. ODP, Sci. Results, 184: 1-8 [Online: <http://wwwodp.tamu.edu/ publications/184_SR/VOLUME/CHAPTERS/214.pdf>

Clement, B., 1991. Geographical distribution of transitional VGPs: Evidence for non-zonal equatorial symmetry during the Matuyama-Brunhes geomagnetic reversal, Earth Planet. Sci. Lett., 104 : 48-58.

Constable, C., and Tauxe, L., 1996. Towards absolute calibration of sedimentary paleointensity records. Earth Planet. Sci. Lett., 143: 269-274, doi:10.1016/0012-821X(96)00128-8.

Glatzmaier, G.A., Coe, R.S., Hongre, L., and Roberts, P.H., 1999. The role of the Earth's mantle in controlling the frequency of geomagnetic reversals. Nature, 401: 885-890.

Gubbins, D., 1999. The distinction between geomagnetic excursions and reversals. Geophys. J. Int., 137: F1-F3.

Guyodo, Y., and Valet, J. P., 1996. Relative variations in geomagnetic intensity from sedimentary records: the past 200.000 years, Earth Planet. Sci. Lett. 143: 23-36. 
Hollerbach, R., and Jones, C.A., 1993. Influence of the Earth's inner core on geomagnetic fluctuations and reversals. Nature, 365: 541-543.

Imbrie, J., Hays, J.D., Martinson, D.G., McIntyre, A., Mix, A.C., Morley, J.J., Pisias, N.G., Prell, W.L., and Shackleton, N.J., 1984. The orbital theory of Pleistocene climate: support from a revised chronology of the marine $\delta^{18} \mathrm{O}$ record. In Berger, A., Imbrie, J., Hays, J., Kukla, G., and Saltzman, B. (Eds.), Milankovitch and Climate (Part.1), Springer, New York, 269-305.

Laj, C., Mazaud, A., Weeks, R., Fuller, M., and Herrero-Bervera, E., 1991. Geomagnetic reversal paths. Nature, 351: 447.

Laj, C., Kissel, C., Mazaud, A., Channell, J.E.T., and Beer, J., 2000. North Atlantic paleointensity stack since $75 \mathrm{ka}$ (NAPIS-75) and the duration of the Laschamp event. Phil. Trans. Royal Soc. London, 358 : 1009-1025.

Laj, C., Kissel, C., and Beer, J., 2004. High Resolution Global Paleointensity Stack since 75 kyrs (GLOPIS-75) calibrated to absolute values, In Timescales of the Geomagnetic Field (American Geophysical Union, Washington, C, 2004), vol. Geophysical Monograph 145: pp 255-265.

Laj, C., Kissel, C., Roberts, A., 2006. Geomagnetic field behavior during the Iceland Basin and Laschamp geomagnetic excursions: a simple transitional field geometry? Geochem. Geophys. Geosystems, 7, Q03004, doi : 10.1029/2005GC001122.

Laj, C., and Channell, J. E. T., 2007. Geomagnetic excursions. Treatise on Geophysics, Vol.5: 373416.

Lisiecki, L. E., and Raymo, M. E., 2005. A Pliocene-Pleistocene stack of 57 globally distributed benthic $\delta^{18} \mathrm{O}$ records, Paleoceanography, 20 : PA1003, doi:10.1029/2004PA001071.

Leonhardt, R., and Fabian, K., 2007. Paleomagnetic reconstruction of the global geomagnetic field evolution during the Matuyama/Brunhes transition: Iterative Bayesian inversion and independent verification. Earth Planet. Sci. Lett., 253: 172-195.

Leonhardt, R., Fabian, K., Winklhofer, M., Ferk, A., Laj, C. and Kissel, C., 2007. The global geomagnetic field during the Laschamp excursion. ASI001, IAGA 2007, Perugia, Italy.

McFadden, P., Barton, C. E., and Merrill, R. T., 1993. Do virtual geomagnetic poles follow preferred paths during geomagnetic reversals? Nature, 361: 342-344. 
Martinson, D.G., Pisias, N.G., Hays, J.D., Imbrie, J., Moore Jr., T.C., and Shackleton, N.J., 1987. Age dating and the orbital theory of the Ice Ages: development of a high-resolution 0 to 300,000-year chronostratigraphy. Quat. Res., 27 : 1-29.

Oda, H., Nakamura, K., Ikehara, T., Nishimura, M., and Khlystov, O., 2002. Paleomagnetic record from Academician Ridge, Lake Baikal: A reversal excursion at the base of marine oxygen isotope stage 6. Earth Planet. Sci. Lett., 202: 117-132.

Paillard, D., Labeyrie, L., Yiou, P., 1996. Macintosh program performs time-series analysis. Eos Trans. AGU 77, 379.

Roberts, A. P., and Winklhofer, M., 2004. Why are geomagnetic excursions not always recorded in sediments? Constraints from post-depositional remanent magnetization lock-in modeling. Earth Planet. Sci. Lett., 227: 345-359.

Shao, J. and Tu, D., 1995. The Jackknife and Bootstrap. Springer Series in Statistics. Springer, $516 \mathrm{pp}$.

Shibuya, H., Iwasaki, Y., Tanaka, H., Hoshizumi, H., 2007. Paleomagnetism of Unzen volcano: A volcanic record (Senbongi excursion) of the Iceland Basin event and the Brunhes VGP distribution for Japan. Earth Planets Space, 59: 763-774.

Wicht, J., 2002. Inner-core conductivity in numerical dynamo simulations. Phys. Earth Planet. Int., 132: 281-302.

Yamamoto, Y., Tanaka, H., Shibuya, H., Hoshizumi, H., and Uto, K., 2006. Absolute Paleointensities From the Unzen Volcano, Japan - Paleointensity Variation During the Last 500 Kyr. AGU Fall Meeting Abstracts, A1292+. 
Figure captions

Figure 1: Map showing the geographical distribution of the sites where the Iceland Basin excursion has been identified in details (after Laj et al., 2006).

Figure 2: Inclination, relative paleointensity (RPI) and planktonic or benthic isotope records available for each core between $250 \mathrm{kyr}$ (marine isotope stage 7) and $150 \mathrm{kyr}$ (marine isotope stage 6). The data from ODP site 983 are from Channell et al. (1997). The data from ODP site 984 are from Channell et al., (1998) and Channell (1999). The magnetic data from sites MD992242, MD99-2247, ODP sites 1145 and 1146 were reported in Laj et al. (2006) as well as the isotope data from cores MD99-2247 (Cortijo, personal communication) and MD99-2242 (C. Hillaire-Marcel, personal communication). Isotope data from ODP sites 1145 and 1146 are from Clemens and Prell (2003) and K. McIntyre and D. Oppo (personal communication) respectively.

Figure 3: a) relative paleointensity records obtained from the different sites after time adjustment (with the record from ODP site 1146 as the reference curve). b) inclination records from the different sites after adjustment made using the paleointensity records. c) effect of the time adjustment on each individual initial age models.

Figure 4: Application of the iterative correlation procedure to $\mathrm{X}, \mathrm{Y}$, and $\mathrm{Z}$ components of paleomagnetic data sets for IBE. Not shown is the matching of the single volcanic spot reading from Unzen, Japan to the initial record ODP1146. The superscripted * at IMIBEa indicates that this model already is based on a calibrated record using the Unzen data point. According to the procedure outlined by Leonhardt and Fabian (2007) the individual paleomagnetic records are correlated to the stepwise improving field evolution model for the respective sampling location. Red colours indicated model predictions, black shows paleomagnetic data. Shaded regions highlight correlated intervals.

Figure 5: age differences between the time scale of the reference record (ODP site 1146) and the time scale resulting from the IMIBEe correlation (see text) 
Figure 6: top part: energy of dipolar and non-dipolar field components from a) SHA and b) IMIBEe approaches. The results from SHA model are reported in arbitrary units and normalized to have the pre-excursional dipole moment $\mathrm{Bo}=1$. Filled bands represent $95 \%$ confidence limits are computed with jackknife statistics. Bottom part: first order (dipolar) Gauss coefficient for the IBE as computed by c) SHA and d) IMIBEe models. Gray bands in SHA model represent the 95\% confidence levels also calculated using the jackknife statistics, no confidence levels are available for IMIBEe model.

Figure 7: Geographical coordinate of dipole axis computed by SHA model compared with VGP paths of sites from Laj et al., 2006. The VGP path of IMIBEe and SHA models show important distinctions due to the difference in first order Gauss coefficients shown in Fig 6. The VGP path of IMIBEe do not reach reverse polarity and does not show much longitudinal variation. These differences are most likely related to the fundamentals of both approaches where the iterative approach finds a solution with least total energy variation to explain the observed and admittedly poorly distributed paleomagnetic data. The SHA model does not have such regularization. 


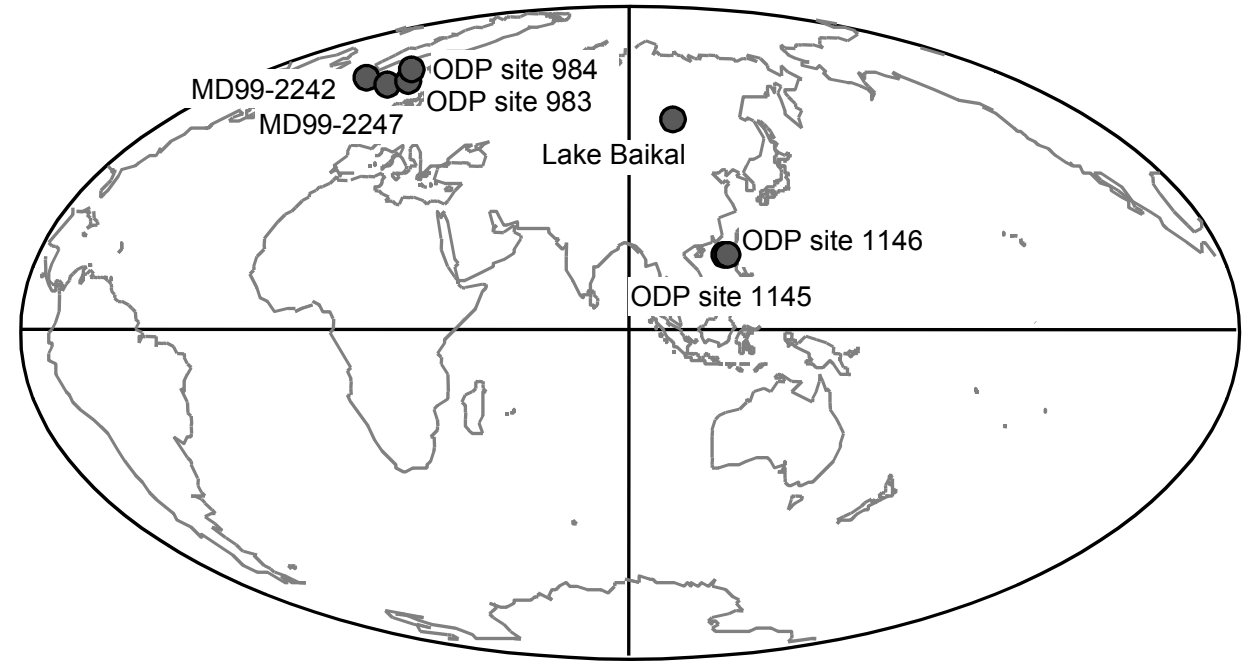

Figure 1 




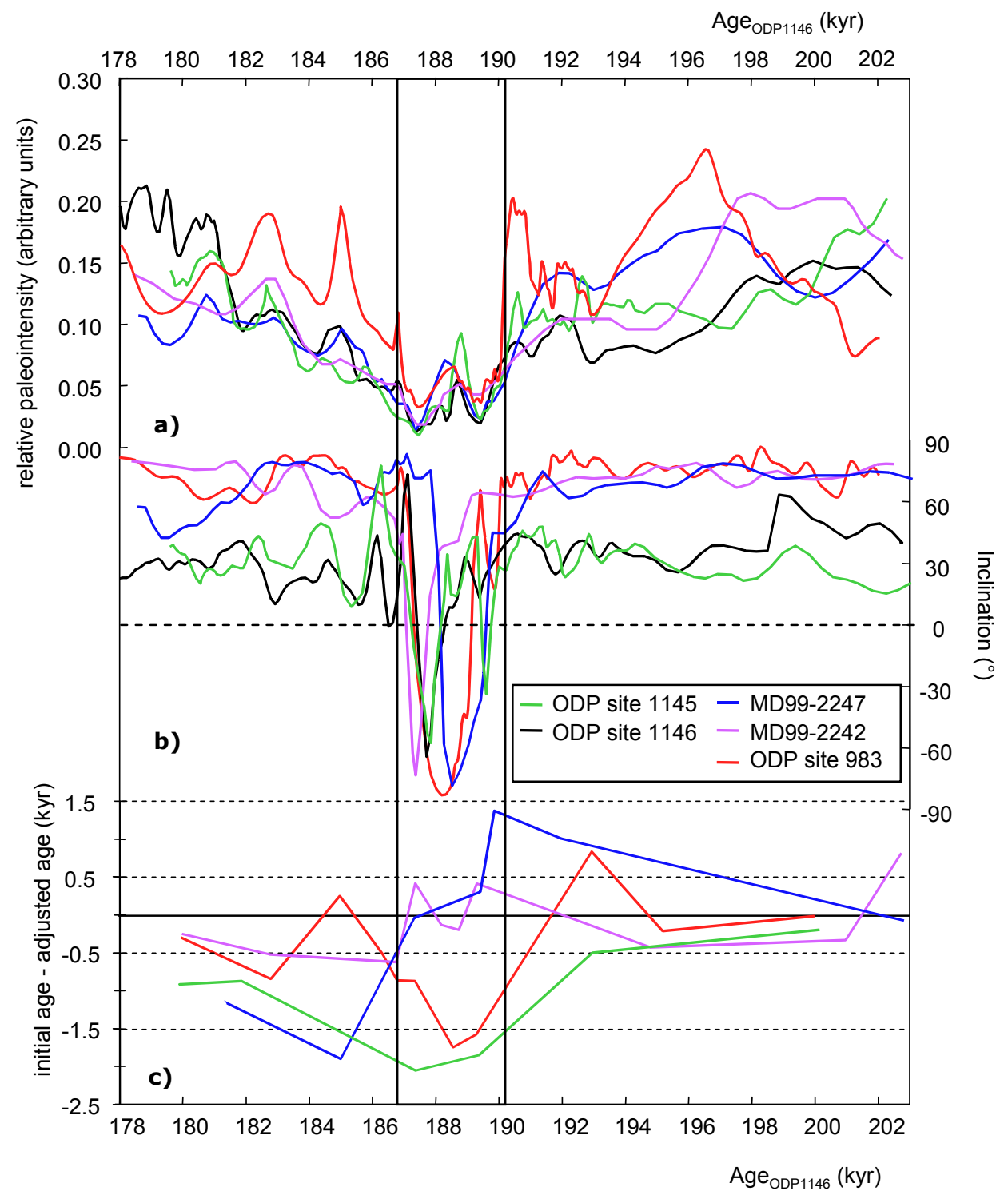

Figure 3 


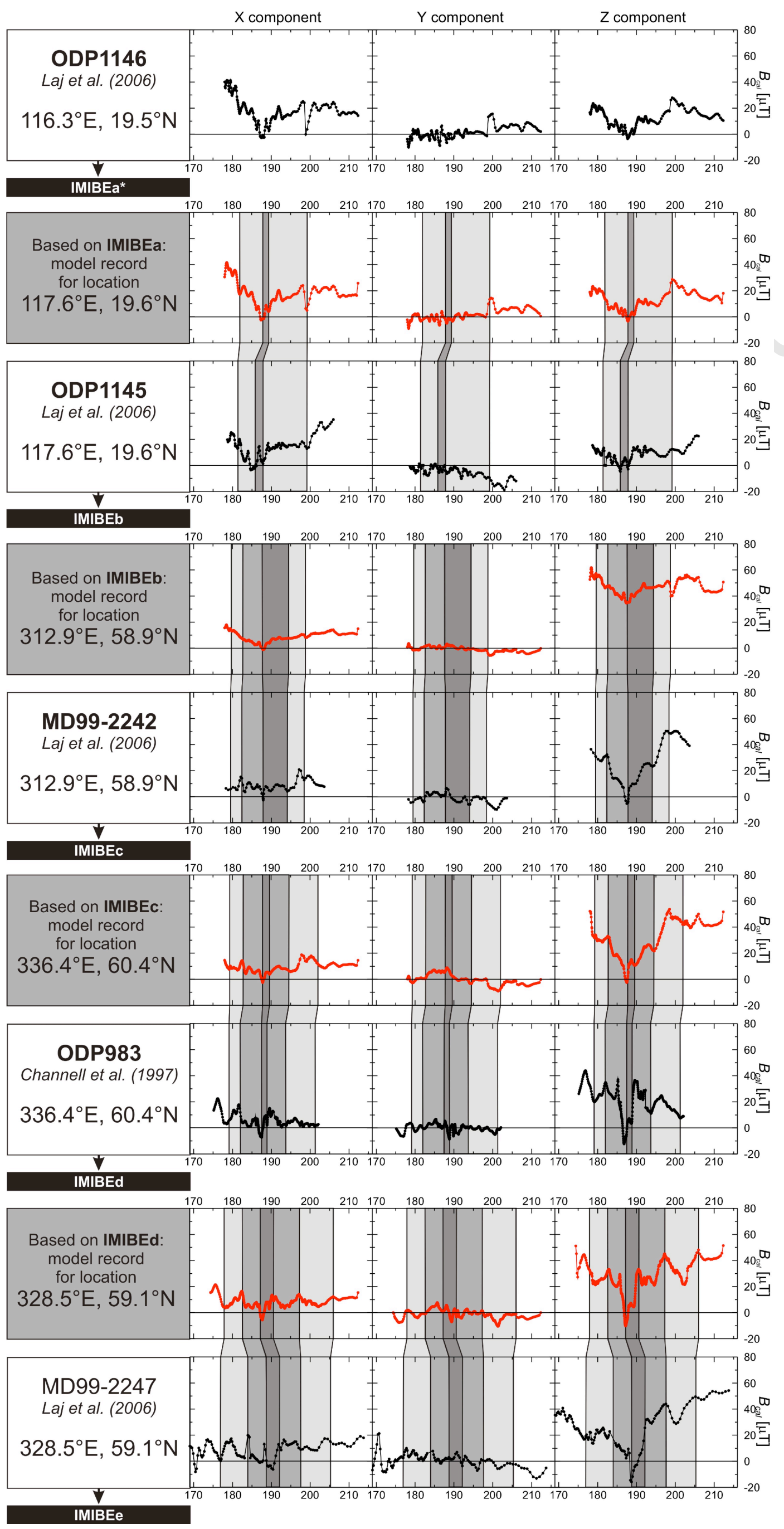

Page 25 of 29 


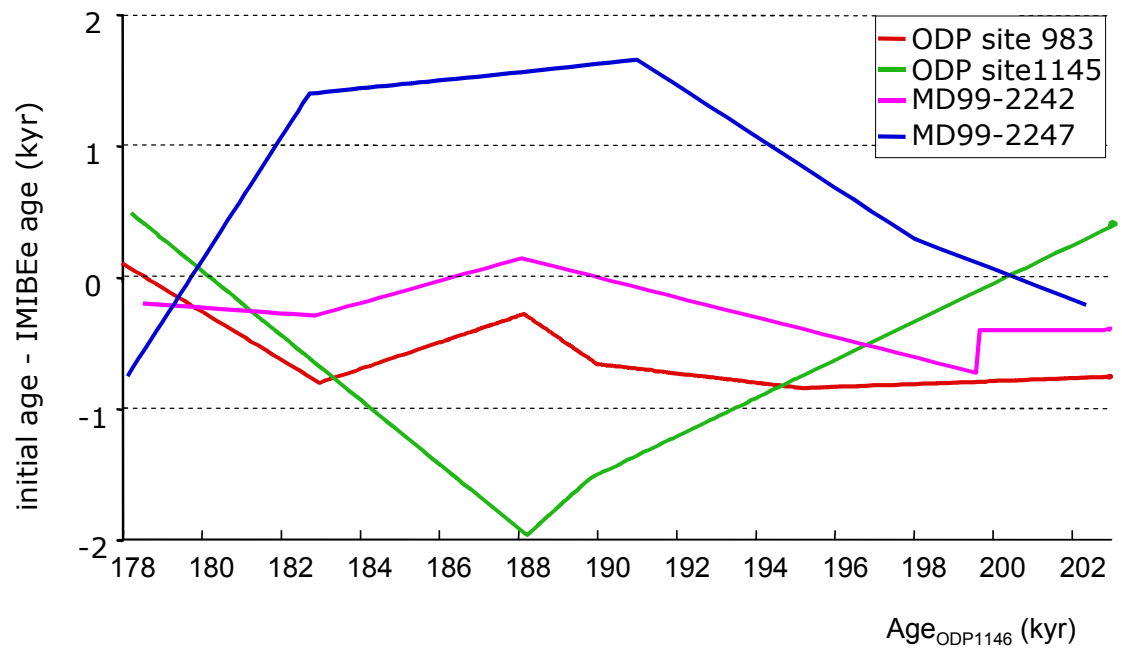

Figure 5 

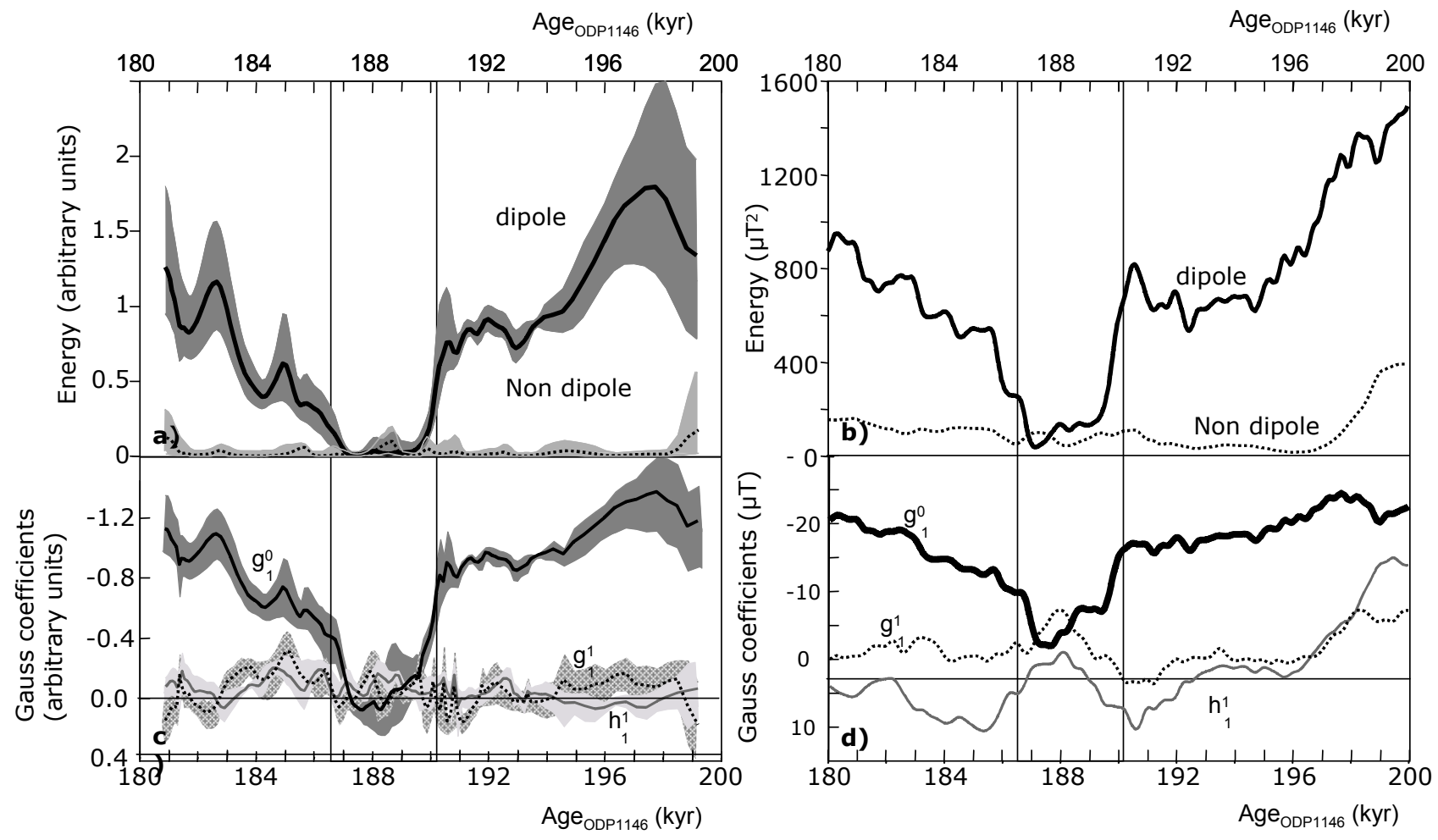

Figure 6 


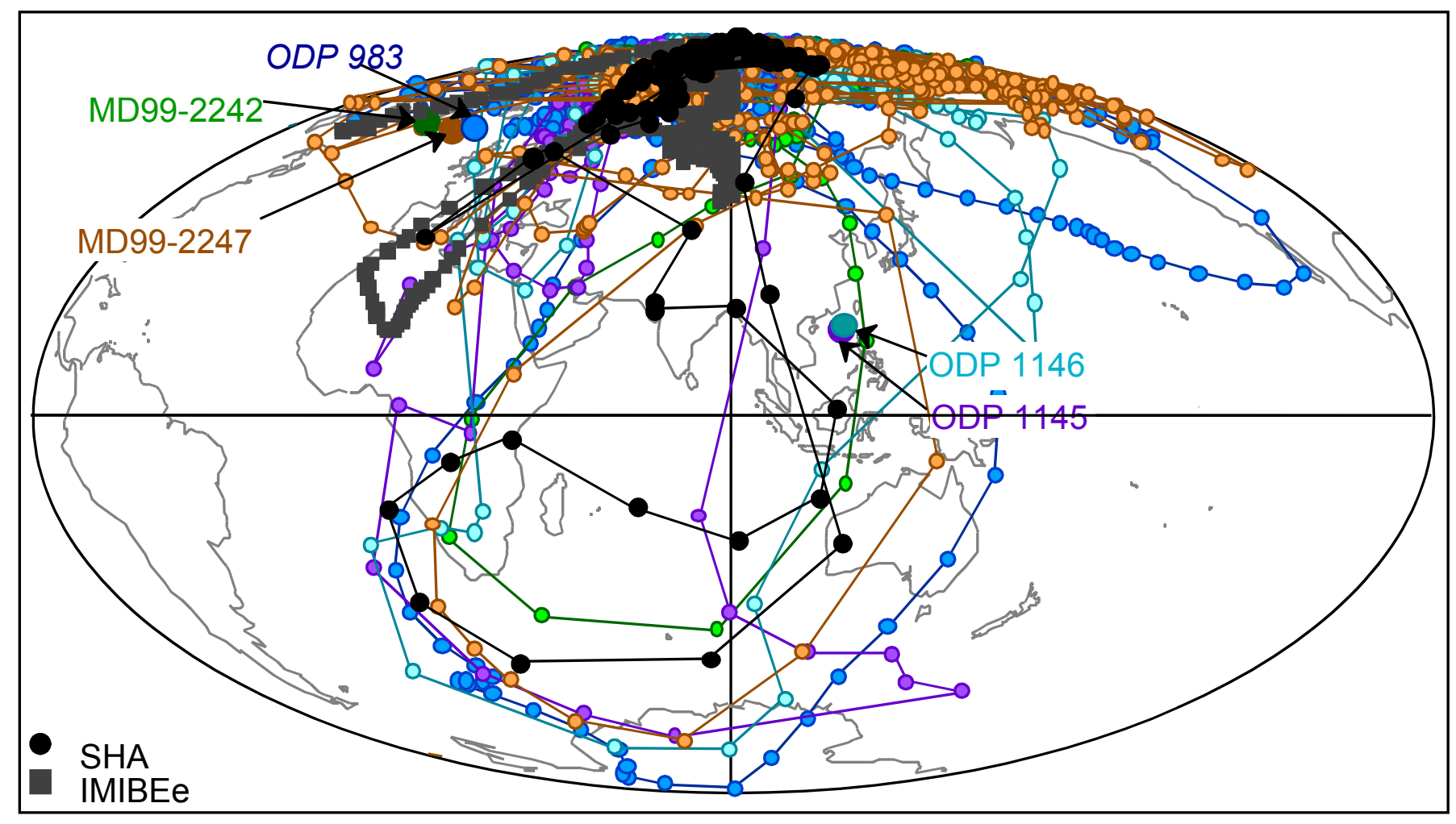

rage 28 of 29 
Table 1. Coordinates and water Depths of the sites where the Iceland Basin excursion has been identified with enough details.

\begin{tabular}{lllll}
\hline Core & Latitude & Longitude & Water Depth & Reference \\
\hline & & & & \\
MD99-2242 & $58^{\circ} 55.06^{\prime} \mathrm{N}$ & $047^{\circ} 07.49^{\prime} \mathrm{W}$ & 2895 & Laj et al. (2006) \\
MD99-2247 & $59^{\circ} 04.61^{\prime} \mathrm{N}$ & $031^{\circ} 28.34^{\prime} \mathrm{W}$ & 1690 & Laj et al. (2006) \\
ODP Site 1146 & $1^{\circ} 27.40^{\prime} \mathrm{N}$ & $116^{\circ} 16.37^{\prime} \mathrm{E}$ & 2092 & Laj et al. (2006) \\
ODP Site 1145 & $19^{\circ} 35.04^{\prime} \mathrm{N}$ & $117^{\circ} 37.86^{\prime} \mathrm{E}$ & 3175 & Laj et al. (2006) \\
ODP Site 983 & $60^{\circ} 24.21^{\prime} \mathrm{N}$ & $023^{\circ} 38.44^{\prime} \mathrm{W}$ & 1983 & Channell et al. [1997] \\
ODP Site 984 & $61^{\circ} 25.51^{\prime} \mathrm{N}$ & $024^{\circ} 04.94^{\prime} \mathrm{W}$ & 1648 & Channell [1999] \\
Lake Baikal & $53^{\circ} 41.65^{\prime} \mathrm{N}$ & $108^{\circ} 21.01^{\prime} \mathrm{E}$ & 335 & Oda et al. [2002] \\
\hline
\end{tabular}

